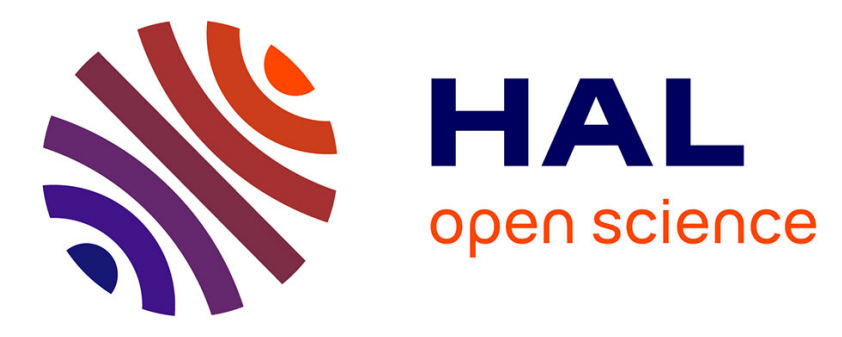

\title{
Gene flow does not prevent personality and morphological differentiation between two blue tit populations
}

Gabrielle Dubuc-Messier, Samuel Caro, Charles Perrier, Kees van Oers, Denis Reale, A. Charmantier

\section{To cite this version:}

Gabrielle Dubuc-Messier, Samuel Caro, Charles Perrier, Kees van Oers, Denis Reale, et al.. Gene flow does not prevent personality and morphological differentiation between two blue tit populations. Journal of Evolutionary Biology, 2018, 31 (8), pp.1127-1137. 10.1111/jeb.13291 . hal-02326707

\section{HAL Id: hal-02326707 https://hal.science/hal-02326707}

Submitted on 22 Oct 2019

HAL is a multi-disciplinary open access archive for the deposit and dissemination of scientific research documents, whether they are published or not. The documents may come from teaching and research institutions in France or abroad, or from public or private research centers.
L'archive ouverte pluridisciplinaire HAL, est destinée au dépôt et à la diffusion de documents scientifiques de niveau recherche, publiés ou non, émanant des établissements d'enseignement et de recherche français ou étrangers, des laboratoires publics ou privés. 


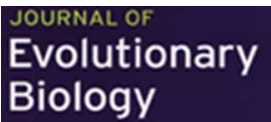

\section{Gene flow does not prevent personality and morphological differentiation between two blue tit populations.}

\begin{tabular}{|r|l|}
\hline Journal: & Journal of Evolutionary Biology \\
\hline Manuscript ID & JEB-2018-00170 \\
\hline Manuscript Type: & Research Papers \\
\hline Keywords: & $\begin{array}{l}\text { Cyanistes caeruleus, genetic divergence, local adaptation, personality, } \\
\text { Phenotypic plasticity, Qst - Fst }\end{array}$ \\
\hline \multicolumn{2}{|l}{} \\
\hline
\end{tabular}


Dear editor,

Montreal, 8 april 2018

Please find enclosed a manuscript entitled "Gene flow does not prevent personality and morphological differentiation between two blue tit populations" that we wish to submit for publication in your journal.

We believe our work will be of interest to the broad readership of your journal because it challenges the general idea that gene flow limits populations genetic divergence and the importance of plasticity versus genetic effects in shaping population divergence for personality traits. We report on a common garden experiment exploring the genetic basis of phenotypic differences observed in the wild for personality, physiological and morphological traits between two blue tit (Cyanistes caeruleus) populations inhabiting contrasting habitats separated by a small spatial scale and connected by gene flow. We raised nestlings originating from the two habitats in aviaries for up to five years and then compared their adult phenotypes. Our results revealed differences similar to those found in the wild, suggesting a genetic divergence for all traits. In addition, $\mathrm{Q}_{\mathrm{st}}-\mathrm{F}_{\mathrm{st}}$ comparisons revealed that the observed quantitative genetic divergence is likely the result of contrasting selection pressures rather than of neutral processes. Our study is one of the first to report $\mathrm{Q}_{\mathrm{st}}-\mathrm{F}_{\mathrm{st}}$ comparisons for personality traits and suggests that genetic divergence is possible at a small spatial scale for behavioural and physiological traits. Such small scale evolution of animal personality and physiology has rarely been reported and shows that population genetic divergence is possible at a small spatial scale for traits generally considered less prone to genetic divergence.

We would like to thank you and the reviewers for providing constructive comments on the first version of the manuscript that we think have greatly improved our work. Please find attached a revised version of our manuscript and a detailed answer to all comments.

We agree for the dataset to be shared on Dryad after the paper is published. The manuscript is not under consideration for publication in another journal. All persons entitled to authorship have been named and have approved the submission of this version of the manuscript. The manuscript is 5978 words.

We hope you will consider for publication in your journal this revised version of our manuscript and we look forward to your assessment.

Best regards,

The authors 


\section{Title}

Gene flow does not prevent personality and morphological differentiation between two blue tit populations.

\section{Authors}

Gabrielle Dubuc-Messier ${ }^{\text {a, b }}$, Samuel P. Caro ${ }^{\mathrm{a}, \mathrm{c}}$, Charles Perrier ${ }^{\mathrm{a}}$, Kees van Oers ${ }^{\mathrm{c}}$, Denis Réale ${ }^{\mathrm{b}^{*}}$, Anne Charmantier ${ }^{\mathrm{a}, \mathrm{b}^{*}}$

\section{Affilitions}

a. Centre d'Écologie Fonctionnelle et Évolutive, Unité Mixte de Recherche CNRS 5175, 1919 Route de Mende, Montpellier Cedex 5, France.

b. Département des sciences biologiques, Université du Québec à Montréal, Case postale 8888, succursale Centre-ville, Montréal (Québec), H3C 3P8, Canada.

c. Department of Animal Ecology, Netherlands Institute of Ecology (NIOO-KNAW), PO Box 50, $6700 \mathrm{AB}$, Wageningen, The Netherlands.

*co-last authors

\section{Running head}

Divergence between blue tit populations

\section{Corresponding author}


Gabrielle Dubuc-Messier: dubuc-messier.gabrielle@courrier.uqam.ca

Université du Québec à Montréal, Département des sciences biologiques, Case postale 8888, succursale Centre-ville, Montréal (Québec), H3C 3P8, Canada.

Tél: 514-987-3000 ext.2265

Fax: 514-987-4647

\section{Acknowledgements}

We thank the landowners for permission to work on their properties and all the blue tit crew for their work, specifically Marta Szulkin, Christophe de Franceschi, Philippe Perret, Virginie Demeyrier, Samuel Perret and Boris Delahaie. We thank Julie Morand-Ferron, Andrew Handry, Arnaud Bechet and Jean-Francois Giroux for their comments. We also thank Marylou Aaldering, Floor Petit, Franca Kropman and Sonja Schaper for taking good care of the birds in captivity. The behavioural tests run at the NIOO-KNAW were approved by the Animal Experimentation Committee of the Royal Dutch Academy of Sciences (DEC-KNAW; permit number CTE09-04 and NIOO11.09). The work performed in the field was approved by the prefectural office of Corsica and the Regional Direction of Environment (DIREN) committee (permit numbers 20090379 and 3467) and the tests run at the CEFE were approved by the Comité Institutionnel de Protection des Animaux (UQAM; CIPA-769-2015; 0413-R1-769-0414) in Canada. This project was funded by grants from the Agence Nationale de la Recherche (BioAdapt grant ANR-12ADAP-0006-02-PEPS), the European Research Council (Starting grant ERC-2013-StG-337365SHE) and the OSU-OREME to AC, by the Natural Science and Engineering Research Council of Canada (Discovery grant) to DR and the Netherlands Organisation for Scientific Research 
(NWO-VENI grant 863.09.011) to SPC. GDM received PhD fellowships from the Fonds de

Recherche Québec Nature et Technologies and the Natural Science and Engineering Research Council of Canada. We declare no conflict of interests. 
Dear Dr Klingenberg,

Thank you for your feedback regarding our manuscript \# JEB-2017-00630. We are very thankful for the new comments you provided as well as those from the two reviewers. We outline below how all these comments have been taken into account to provide a revised version of our manuscript that will now, we hope, be accepted for publication in Journal of Evolutionary Biology.

\section{Comments from Editor}

In my own reading of your paper, I have come across the act that you used the method of random skewers for comparing $P$ matrices. This method has been criticised for lack of power and other statistical properties. Very recently, such a critique has been published by Jim Rohlf. Please have a look at this paper and think how the criticism applies to your analysis. I am not prescribing a particular course of action to you, but I would like you think about it as part of the further revisions.

>> Since the Qst, Pst and Fst comparison is more robust and provides stand-alone results that do not necessitate any complementary analysis, we have decided to remove the matrix comparison done with the random skewer method that has been recently criticized. This does not change any conclusion from the manuscript, but it should remove any doubt regarding random skewers.

+++++++++++++++++++++++++++++++++++

Comments from reviewer 1

I have only two comments:

1. - The first one refer to the use of the term phenotypic plasticity (or plastic response) as synonym of environmental factors affecting phenotypes. I think it may confound readers and, whenever possible, I suggest the used of environmental factors throughout the manuscript. This is because phenotypic plastic response to environmental condition may have a genetic component (see for instance Charmantier et al. (2008), Science) and, thus, phenotypic plastic responses may be due not only to environmental factors, but to genetic factors. Remember that the reaction norms may have strong genetic components, but you use plasticity as solely reflecting environmental effects. Traditional terms used in quantitative genetics are genetic, environmental and maternal effects and, thus, would strongly recommend the used of "environmental factors" instead of plasticity.

>> We partly disagree here with the reviewer's opinion that our use of the term "plasticity" brings confusion in all its use. We now clarify that by plasticity we refer to "the adjustment of individual phenotypes in response to environmental factors" (definition provided in line 30). Note that plasticity does not result in a genetic change, however variance in plasticity can have a genetic origin when plasticity is heritable and lead to evolution of different plasticity across populations. Although this is a side issue to our study, we now explain this in lines 65 to 68. Finally, when addressing the issue of the Qst/Pst comparison, we have followed the reviewer's advice and changed plasticity to environmental factors (lines 119 and 454).

2. - The second comment refers to the scarce information provided for used mixed model. You should explain how mixed models accounted for the structure of the data set (random blocks) (see for instance Schielzeth, H. \& Forstmeier, W. (2009). Conclusions beyond support: overconfident estimates in mixed models. Behav Ecol 20: 416-420). Do you used random 
intercept, random slope, or random intercept-and-slope models? Was identity of rearing brood nested within identity brood of origin? In the case of bird identity, this random factor should be nested within the interaction between brood of origin and rearing brood (or, in the case of a completely hierarchized structure of random factors, at the lower level). Remember that a correct definition of hierarchized random blocks is essential for proper estimations of genetic and environmental factor explaining phenotypic variation.

>> Thank you for pointing out this imprecision. We used random intercepts for bird identity, brood of rearing and brood of origin. We now clarified this (L249 to 253).

\section{Comments from reviewer 2}

Comments on your written responses:

1. Re. my comment 12 : I meant that care takers may not have fed blind with respect to origin. While I don't really think there are box/nest/location, date or care taker effects, some readers may disagree, so perhaps it is best to mention these possibilities and state why you discard it. I think it is always a strength of a paper if it presents (and if space permits) discusses its potential weaknesses, as long as it doesn't distract.

>> The populations that we study here differ in many traits, one of them being phenology (i.e. timing of reproduction). Because of this timing difference, raising the chick at the same time is impossible. We have made every effort possible for keeping the birds of the two populations into the same conditions, but for sure there are many little, sometimes unidentified, differences, that were impossible to control. Temperature was certainly a bit different (later in the season for the Fango birds), as well as humidity, photoperiod, they travelled in a different boat, etc. among which are the rearing conditions (caretakers, etc). Thus, it is impossible to pinpoint and inventory the exact differences that might have been of relevance to the birds. We have therefore clarified this timing difference between the populations (see L151 to 157), but we believe it is not possible to discuss it much further since we do not know if there were any relevant difference (and which ones) that the birds could have cued on despite our efforts to homogenize their environments and experiences.

2. Re. comment 41: you don't address the concern of multiple testing, so no mention of the need for correction for a large number of tests, which inflate the probability to find significant results. So Bonferroni correction or something similar might be called for.

>> Bonferroni corrections have been criticized for being too conservative (Moran 2003). However, applying a Bonferroni correction to our results would lead to the same conclusions as we found a p-value $<0.01$ for all study traits except body mass. If the editor deems it useful, we can add this information in the results section but prefer not to.

Moran, M. D. (2003). Arguments for rejecting the sequential Bonferroni in ecological studies. Oikos, 100(2), 403-405.

And instead of Wright, I meant Fisher 's method

(https://en.wikipedia.org/wiki/Fisher\%27s method), which to my opinion can also be used as a within-study meta-analysis. You repeatedly test the same hypothesis, just changing the response variable. So you could apply Fisher's method to the p-values obtained for the habitat of origin tests. 
>> We now use this test. We provide this information and the results of this test in lines 262 to 264 and 306 to 308 ( $p$-value $\left.=3.675 \times 10^{-8}\right)$.

3. Re. comment 46: with evergreen habitat being atypical, I mean not the habitat itself but in the evolutionary history of the Blue tit, assuming that the species is largely adapted to deciduous trees and that colonisation of evergreen forest is relatively recent, or that gene flow will be mostly from deciduous to evergreen populations (given the relative population sizes of Blue tits in each of the habitats at a large, European?, scale). Then, even if Blue tits in evergreen habitats are exposed to specific selection pressures and have actually evolved in that direction, that doesn't mean that they are now adapted - there may still be an evolutionary lag. In fact, if you found directional selection on traits *within* a habitat, this would confirm local maladaptation. Whether or not size-corrected body mass is a good measure of overall condition (whatever that is) in ad libititum fed, captive birds, is debatable, but I'm thinking of effects that are more general for maladaptation, such as maternal stress hormones or lack of micronutrients deposited in eggs affecting overall development (body, physiology, brain, behaviour). Again, I don't know if this is likely, but if you think it is not, then explaining this in the paper might be the best way forward.

>> We agree that ongoing selection can be a sign of maladaptation. We also agree that we cannot completely exclude that early environmental effects such as maternal effects occurring before and soon after the chicks were sampled from their nest were at least partly responsible for the observed patterns. We discussed this possibility in length in lines 358 to 377.

Comments on the new version:

4. L 36: Edelaar \& Bolnick 2012 TREE is also a useful citation in this section >> We added this citation (L36)

5. L 53: and/or (you don't need both) >> We modified the sentence (L51)

6. L 54: also Richardson et al. 2014 TREE microgeographic divergence >> We added this citation (L52).

7. L 67: given that you (correctly) scale you question to the dispersal distance, whether a species is highly mobile or not is now unimportant, so remove that part after the comma.

>> We changed the sentence (L65).

8. L 110: I like the layered approach to the issue of divergence in this paper, with three different analyses/data sets.

>> Thank you for the positive comment. 
9. L 110: in this section you need to introduce the issue of Pst and Qst, explain what Pst is (not so commonly known), and why/that you will assume that the Pst of lab-reared birds should approximate Qst to a greater degree than the Pst of wild birds. (see L 106-107, where you do mention that $P$ approximates $G$ ), if there is plasticity in the wild.

>> We added some details and explanations on this topic in L103 to L122.

10. L 144: do you actually know this? (I assume the birds were ringed)

>> We meant they were assigned randomly to a cage (L148).

11. L 145: fed ad libitum (saturation)?

>> ad libitum means that there was always food and water available for the birds. We never force-fed any bird, neither were they food-restricted. This term is commonly used in the literature.

12. L 153: tarsus at which age?

>> Adult (>1 year of age), we now provide this information (L164).

13. L 188: blind with respect to what?

>> We now provide this information (L199).

14. L 211: what percentage of SNPs did you remove for being potentially under selection? I suppose this must be well under $1 \%$. Nonetheless, many of these outliers will be false positives, i.e. highly divergent SNPs that actually are neutral and therefore should not be filtered out. So you are caught between a rock and a hard place. Perhaps, to obtain a conservative (upper) estimate for Fst, you could also report what value you obtain without this filtering step, so just overall genomic divergence.

$>$ We removed $0.7 \%$ of the total number of SNPs. We now provide this information (L223). Including or excluding SNPs putatively under divergent selection (Fst of 0.004 and 0.006 respectively) provided high Qst/Fst ratio in both cases. Excluding loci putatively under selection therefore had little effect on the general conclusion, (which is expected in a context of putatively highly polygenic traits and very low genetic differentiation among populations, resulting in few outliers SNPs of large effects and high differentiation).

15. L 245: check use of singular/plural

>> Done (L257)

16. L 265-266: so move this introduction up, to line 110

>> Done (L114 to 117).

17. L 278: habitat of

>> Done (L279-280) 
18. L 279: and individual in the case of body mass? So basically, all random effects variances plus residual variance?

>> Yes, we now provide this information (L280-281)

19. L 280: this is the Pst for wild birds? Why not include the random effect of brood?

>> These birds were measured once adult, for many of them we did not know the brood of origin.

And I guess observer is random here, because many people were involved?

>> Yes, L288

But did you then include this observer variance component into the within-population variance? (For Pst you don't specify which variances were used to calculate the withinpop variance component).

>> Yes, we now provide this information (L287 to 289)

This to me would not seem correct, since observer effects are not within-population genetic variation (as mentioned before in my comment 34 of the previous revision). The same might actually be true for rearing brood effect: this could be indirect genetic effects, but could also be purely or mostly environmental. And the same issue for the residual variance: to what extent is this genetic variance, or just unexplained environmental noise around the genotypic value? I think you now assume it is fully genetic. (Note that I'm partly disagreeing with myself, re. comment 34 last review).

What I'm missing in this section is an explanation/justification of which variables are or are not included in the between- and within-population variance components, and methodological/theoretical citations to back this up. And then the effects of the assumptions and decisions on results made should be discussed later on.

>> We rewrote partly this paragraph and hope that it is now clearer (L275 to 289). For Qst calculation, fallowing the reviewer's comments, we decided to calculated $\sigma_{B}$ as the variance attributable to habitat of origin and $\sigma_{W}$ as the residual variance (or for body mass as the sum of the variance attributable to the residual and to the individual identity). We did not include any broods effects in these models anymore because the variance attributable to the brood is also attributable to the population of origin in our case. These changes did not affect our conclusions. We changes the results in Table 2 and S5.

In our opinion, the observer effect should not be included in the between population variance for Pst calculation but could be considered as residual variance in the context of our analysis. This is why we calculated $\sigma_{B}$ as the variance attributable to habitat of origin and $\sigma_{W}$ as the sum of the variance attributable to the observer and to the residual variance and the individual effect (L287 to 289). 
20. L 285: I think you mean slightly informative priors? Slightly UNinformative means very informative.

>> Yes, we changed the sentence (L292)

21. L 286: I'm surprised you stay with a burn-in of 500 iterations, when running a model of 10 million iterations. Normally the burn-in is more like a third or half of the total iterations. With a thinning of 200 , you now discard only the first 2 effective samples, and keep the remaining 50,000 samples. So basically, you have no burn-in period. I propose a burn-in of at least 1 million iterations, unless you know that your chains converge very quickly (in which case you don't need 10 million iterations, which looks like overkill anyway).

>> We compared models with different burn-in period, iterations and nu and found no important difference between these models and really small autocorrelation (L291 to 297).

22. L 295: maybe this information goes better with line 278 ?

>> Yes, we agree, we changed the location of the sentence to L283-284.

23. L 331: I still don't get this result: you state that the two matrices are more similar to each other than two random matrices. This is very unsurprising. And irrelevant. What we want to know is if they are dissimilar, as you claim you will test in $L 108$. But you don't do that. I mentioned this before. I think this analysis is not relevant at all - look for an analysis that will tell us if the matrices are identical or not (e.g. if your correlation of 0.9 is different from 1.0, not if it is different from 0.0 , but probably random skewers is not the thing to do).

>> This comment is in line with the Editor concern regarding the random skewer method. As explained in our response to the Editor, we have removed this comparison.

24. L 338: extent

>> We removed this part of the sentence

25. L 343: suggests

>> Modified (L343)

26. L 349: replace cannot be for is not

>> Modified (L349)

27. L 351: indicates

>> Modified (L351)

28. L 353: remove genetically

>> Removed 
29. L 354: replace cannot for does not

>> Modified (L355)

30. L 355: replace could be for are

>> Modified (L356)

31. L 360: remove genetic

>> Removed

32. L 367: mention here also the significant effects you found for rearing brood, suggesting the acting of such early effects

>> We discuss the rearing brood effects in lines 433 to 443.

33. L 387: or that you removed high Fst neutral ones

>> We now mention this possibility (L387) but we choose to keep it in parenthesis since this issue is not important and not discussed further.

34. L 388: but you should not use microsatellites for Qst-Fst comparisons, see several papers on this by Jost, Edelaar and other authors, in Molecular Ecology (partly cited in Leinonen et al. 2013).

>> Yes, this is why we did not use microsatellites in this study, the microsatellite study is mentioned to discuss the Fst level.

35. L 390: this statement needs to be re-evaluated after checking what SNP filtering does, and whether the Qst calculations are changing based on my comments above.

>> This statement still holds after re-evaluation of the consequences of the filtering.

36. L 397: paper by Dingemanse et al. on predator-presence related population divergence in stickleback personalities also comes to mind (J Anim Ecol?)

>> We added this reference (L398)

37. L 400: studies

>> Modified (L419)

38. L 404: better refer to the Qst values in Table 2?

>> Modified (L404)

39. L 413: I agree, but also mention/discuss if you would expect the traits you used to be correlated in your variance covariance matrix (which they are hardly) 
>> As explained in our response to the Editor, we have removed the comparison between the covariance matrices form the manuscript.

40. L 428: again, you tested if they are similar, but you should test if they are different >> This section was removed.

41. L 435: associated with >> Modified (L431)

42. $L$ 445: remove ( 2 to 12 days) since this is irrelevant - statistical power is the issue, not the time frame.

>> We agree, we changed the location of the parenthesis in the sentence (L441).

43. $L$ 447: this is the same as your first argument - effectively not sensitive relative to other environmental effects

>> We removed this sentence

44. L 459: again, this may need to be revised depending on any Qst and Pst recalculations. It is kind of strange that divergence is not reduced under a common environment, assuming that any plasticity in the wild would tend to operate in the direction of the divergent selection between habitats. I think this is also the common observation (often even no remaining divergence in a common environment).

>> We meant that the environmental effects might not be very high in the wild otherwise we would have found a $P_{\text {st }}$ significantly different from the $Q_{s t}$. See our response to previous comments about the filtering.

45. L 463: remove phenotypic

> Done.

46. $L$ 464: replace $L$ 465-466 by: but that genomically are diverged much less.

>> We prefer the original sentence.

47. L 466: replace past study on by past results for

>> Done (L461).

48. L 470: scales (relative to dispersal ability) for

>> Done (L464).

Table S6: for HR and tarsus length, the mean is higher than the credible interval, so this needs to be fixed 
>> We corrected this information (Table S5).

Table 1: as far as I'm concerned (and you, as you don't test its significance), you can remove the info for the intercepts).

Time of day: based on d.f. you fitted a linear effect - have you checked if the effect is actually non-linear?As you have enough data, perhaps fit time as categorical (by hour for example). Same for age. This might change (improve?) your Qst estimates, see L 338.

>> We have only fitted here a linear effects.

+++++++++++++++++++++++++++++++++++ 


\section{Abstract}

2 Understanding the causes and consequences of population phenotypic divergence is a central goal

3 in ecology and evolution. Phenotypic divergence among populations can result from genetic

4 divergence, phenotypic plasticity or a combination of the two. However, few studies have

5 deciphered these mechanisms for populations geographically close and connected by gene flow,

6 especially in the case of personality traits. In this study, we used a common garden experiment to

7 explore the genetic basis of the phenotypic divergence observed between two blue tit (Cyanistes

8 caeruleus) populations inhabiting contrasting habitats separated by $25 \mathrm{~km}$, for two personality

9 traits (exploration speed and handling aggression), one physiological trait (heart rate during

10 restraint) and two morphological traits (tarsus length and body mass). Blue tit nestlings were

11 removed from their population and raised in a common garden for up to five years. We then

12 compared adult phenotypes between the two populations, as well as trait-specific $\mathrm{Q}_{\mathrm{st}}$ and $\mathrm{F}_{\mathrm{st}}$. Our

13 results revealed differences between populations similar to those found in the wild, suggesting a

14 genetic divergence for all traits. $\mathrm{Q}_{\mathrm{st}}-\mathrm{F}_{\mathrm{st}}$ comparisons revealed that the traits divergences likely

15 result from dissimilar selection patterns rather than from genetic drift. Our study is one of the

16 first to report a $\mathrm{Q}_{\mathrm{st}}-\mathrm{F}_{\mathrm{st}}$ comparison for personality traits and adds to the growing body of

17 evidence that population genetic divergence is possible at a small scale for a variety of traits

18 including behavioural traits.

\section{Keywords}

21 Cyanistes caeruleus, genetic divergence, local adaptation, personality, plasticity, $\mathrm{Q}_{\mathrm{st}}-\mathrm{F}_{\mathrm{st}}$ 


\section{Introduction}

24 Understanding the evolutionary causes of phenotypic divergence among populations is an

25 important aspect of the study of diversity. Environmental heterogeneity can have a major role in

26 generating phenotypic divergence among populations (Wang \& Bradburd 2014). Spatial variation

27 in selection pressures resulting from such environmental heterogeneity can lead to genotype by 28 environment interactions for fitness and produce phenotypic and genetic divergence between

29 populations that can lead to local adaptations (Kawecki \& Ebert 2004; Wang \& Bradburd 2014).

30 Spatial heterogeneity in ecological conditions can also favour the evolution of phenotypic

31 plasticity, i.e. the adjustment of individual phenotypes in response to environmental factors

32 (Pigliucci 2005) and cause phenotypic divergence of populations in the absence of genetic

33 divergence or local adaptation (Sultan \& Spencer 2002; Réale et al. 2003; Pigliucci 2005).

34 Phenotypic divergence of populations can also be produced by non-random dispersal of

35 individuals between habitat types (Wang \& Bradburd 2014). Importantly, phenotypic divergence

36 of populations does not necessarily involve an adaptive process since phenotypic plasticity and

37 non-random dispersal can be non-adaptive (Edelaar \& Bolnick 2012; Fitzpatrick 2012; Wang \&

38 Bradburd 2014) and can occur in the same or in the opposite direction to genetic divergence

39 (Fitzpatrick 2012). In addition, strong founder effects or genetic drift can also lead to phenotypic

40 and genetic divergence of populations (Slatkin 1987). Establishing the relative importance of

41 environmental versus genetic effects involved in the phenotypic divergence of populations

42 provides fundamental information about the origin of intra-specific diversity in the wild. In

43 addition, determining if this divergence is adaptive or the result of neutral processes is essential

44 because it gives important indications about the eco-evolutionary dynamics of traits and their

45 evolutionary trajectories. 
47 Traditionally, it has been considered that the homogenizing effect of gene flow prevents genetic 48 divergence of populations (Sultan \& Spencer 2002; Lenormand 2002). Thus, most research on

49 genetic divergence focused on populations separated by large spatial scales or by important 50 landscape barriers to dispersal (Slatkin 1987; Lenormand 2002). Nevertheless, recent theoretical 51 and empirical studies revealed that even in the presence of gene flow, phenotypic divergence can 52 have a genetic origin when there is strong divergent selection and/or non-random dispersal 53 (Richardson et al. 2014; Wang \& Bradburd 2014). Despite growing interest for such isolation by 54 environment, there is little empirical data on the mechanisms underlying the phenotypic 55 divergence of populations separated by small geographic distances and connected by gene flow.

57 Behavioural traits have often been considered as highly plastic and thus less prone to genetic 58 divergence. However, several studies are now showing that among-individual differences in 59 behaviour can be repeatable (personality; Réale et al. 2007), heritable (van Oers \& Sinn 2011), 60 and related to fitness (Smith \& Blumstein 2008) and could thus evolve in response to local 61 conditions. In this context, an increasing number of studies have compared the personality 62 phenotypes of individuals inhabiting contrasted ecological conditions (Bell 2005; Quinn et al. 63 2009; Atwell et al. 2012; Herczeg et al. 2013; Miranda et al. 2013; Karlsson et al. 2016; Jacquin 64 et al. 2016). However, fewer studies have disentangled the role of plasticity from that of genetic 65 effects in shaping phenotypic divergence between populations separated by distances that are 66 within the dispersal ability of a species (Atwell et al. 2012; Miranda et al. 2013). Note that the 67 plastic response to environmental factors can itself have a genetic basis, hence plasticity levels 68 can differ across populations because plasticity can be heritable and evolve differently across 69 populations (e.g. Laurila et al. 2002). 
71 Previously, we have revealed a phenotypic divergence for personality and morphological traits 72 between two wild populations of blue tits (Cyanistes caeruleus) living in contrasting habitats in a

73 Mediterranean landscape (Charmantier et al. 2016; Dubuc-Messier et al. 2017). These

74 populations occupy habitats and valleys dominated by either evergreen (holm oak, Quercus ilex)

75 or deciduous oaks (downy oak, Quercus pubescens) yet are separated only by $25 \mathrm{~km}$, which is

76 within the typical dispersal range of the species (Tufto et al. 2005; Winkel \& Frantzen 1991). The

77 dominant tree species in each habitat and valley is suspected to have an important influence on

78 blue tits' ecological context that translates into phenotypic divergence between populations for

79 numerous types of traits despite a spatial proximity and gene flow among them (Charmantier et

80 al. 2016). For example, blue tits from the evergreen habitat have a higher adult survival

81 probability, a lower body mass, a smaller tarsus length, a higher docility (lower handling

82 aggression), and a slower exploration in a novel environment, compared to birds from the

83 deciduous habitat (Table S1; Grosbois et al. 2006; Charmantier et al. 2016; Dubuc-Messier et al.

84 2017). In addition, past studies in this system revealed that small birds (mass and tarsus length)

85 have a selective advantage in the evergreen habitat (Blondel et al. 2002; Teplitsky et al. 2014),

86 suggesting that at least some of the observed phenotypic divergence between habitats could be 87 adaptive.

88

89 In this study, we used a common garden experiment to assess whether the personality and 90 morphological divergence between these two blue tit populations could have a genetic basis. We 91 collected blue tit nestlings from the evergreen and deciduous habitats and raised them for up to 92 five years in aviaries, subsequently comparing their personality, physiological and morphological 93 phenotypes once adults. Previous experiments in aviaries on this system have found a genetic 
94 divergence between these habitats for life-history traits (Lambrechts et al. 1997). Based on these

95 results, we hypothesized that the phenotypic divergence found previously in the wild for 96 personality and morphological traits would also reflect a genetic divergence. Therefore, we

97 predicted that, following the common garden experiment, individuals originating from the 98 evergreen habitat would show a slower exploration in the novel environment, a higher docility

99 (lower handling aggression), a smaller tarsus and a lower body mass then individuals originating 100 from the deciduous habitat. We also compared heart rate during manual restraint of birds 101 originating from the two habitats, a physiological measure of stress reaction often used in 102 personality studies (Koolhaas et al. 1999).

103

104 Second, we investigated whether the potential genetic divergence between these habitats could be

105 attributed to different selection pressures or to genetic drift using a $\mathrm{Q}_{\mathrm{st}}-\mathrm{F}_{\mathrm{st}}$ comparison approach

106 (Leinonen et al. 2013). A trait $\underline{Q}_{\text {st }}$ measures the amount of additive genetic variance among

107 populations relative to the total genetic variance in the trait (Leinonen et al. 2013). Fst is the

108 equivalent measure for neutral molecular variance (Weir and Cockerham 1984) and can be used

109 as a null expectation for the degree of population divergence due to genetic drift and gene flow. If

$110 \underline{\mathrm{Q}_{\mathrm{st}}}>\mathrm{F}_{\underline{\mathrm{st}}}$, the trait divergence is higher than the neutral expectation and is likely the result of

111 directional selection favouring local adaptation (Leinonen et al. 2013) rather than the result of

112 drift. The two blue tit populations have very large effective population sizes (roughly estimated

113 around 10,000 in each valley, Perrier et al., genomic work in progress) and have been found

114 weakly genetically differentiated (Szulkin et al. 2016). Consequently, it is unlikely that any

115 genetic divergence for these traits would be produced by genetic drift. We considered that,

116 because birds were raised in a common garden, a phenotypic difference among individuals was a

117 realistic approximation of an additive genetic effect. We thus used the phenotype of the common 
118 garden birds to calculate the $\mathrm{Q}_{\mathrm{st}}$ and predicted that the $\mathrm{Q}_{\mathrm{st}}$ of each trait would significantly exceed

119 the $\mathrm{F}_{\mathrm{st}}$ estimated between both populations. In addition, in order to better understand the

120 importance of environmental factors in shaping the observed phenotypic differentiation in the

121 wild, we compared the genetic differentiation $\left(\mathrm{Q}_{\mathrm{st}}\right)$ of birds from the common garden experiment

122 with the phenotypic differentiation of wild birds for the same traits $\left(\mathrm{P}_{\mathbf{s t}}\right.$; the amount of

123 phenotypic variance among wild populations relative to the total phenotypic variance in the trait).

\section{Materials and Methods}

126 The population located in the evergreen habitat (Evergreen-Pirio) is in the Corsican Fango valley $127\left(42^{\circ} 34^{\prime} \mathrm{N}, 08^{\circ} 44^{\prime} \mathrm{E} ; 200 \mathrm{~m}\right.$ elevation) and contains 205 nest-boxes distributed across two study

128 plots. The population located in the deciduous habitat (Deciduous-Muro) is in the Corsican 129 Regino valley $\left(42^{\circ} 32^{\prime} \mathrm{N}, 08^{\circ} 55^{\prime} \mathrm{E}, 350 \mathrm{~m}\right.$ elevation) and contains 110 nest-boxes distributed 130 across three study plots. A weekly to daily monitoring over the course of the breeding season 131 (from early April to the end of June) allowed the recording of exact laying dates and hatching 132 dates for all broods established in nest boxes.

134 Nestlings were collected for the common garden experiment at 7 to 12 days of age and were 135 brought to the Netherlands Institute of Ecology (NIOO-KNAW, Wageningen, Netherlands)

136 where they were hand raised under standardized conditions. We used 169 blue tits that were 137 collected in 2010 and 2011 in the deciduous habitat (2010: 42 birds, 7 broods; 2011: 39 birds, 6 138 broods) and in the evergreen habitat (2010: 44 birds, 10 broods; 2011: 44 birds, 8 broods). In 139 2010, before collecting chicks, broods were cross-fostered between nests for another experiment. 
140 For this experiment, at 2 to 4 days old, half of the chicks from a given brood were exchanged

141 with half of the chicks of another brood from the same population.

142

143 Once collected, all birds were transported by car and hand-fed from Corsica to the Netherlands,

144 and were hand reared until independence as described in Reparaz et al. (2014). Briefly, all the

145 chicks from a given habitat and year were kept in boxes divided into multiple compartments that

146 were not isolated from one another, each compartment containing one nest of 3 to 5 nestlings,

147 until fledgling. Chicks from adjacent nests could easily change compartment, meaning that chicks

148 from different nests were quickly mixed. After fledgling, birds were housed in cages in groups of

1492 to 4 birds, irrespective of their sex and nest of origin (assigned randomly). Up to that period,

150 chicks were fed every half-hour, 14 hours per day (7:00 am - 9:00 pm), with a diet consisting of a

151 mixture of curd cheese, ground beef heart, baby cereal, multivitamin solution and calcium

152 carbonate, supplemented with wax moth larvae and bee larvae, until independence. Raising

153 chicks from the different habitats at exactly the same time would have been ideal but was

154 impossible because chicks in the Regino and the Fango valleys hatch one month apart. However,

155 chicks from different nests and habitats could easily see and hear each other, as they were raised

156 in the same rooms, and fledglings from the Regino valley were still present in the cages when the

157 younger chicks from the Fango valley arrived in the laboratory. Caretakers were the same for

158 birds of different origins.

160 At independence, about 35 days after hatching, birds were relocated to larger individual cages or

161 aviaries. Food and water were provided ad libitum. In 2012 and 2015, birds were moved to the

162 Centre d'Écologie Fonctionnelle et Évolutive (CEFE-CNRS; Montpellier, France), where they

163 were kept in outdoor aviaries before being released back into their natal habitat in Corsica. 
164 Morphological measurements were taken during the period at the NIOO-KNAW. Tarsus length

165 was measured once (at $>1$ year of age) but body mass was measured several times, always by the

166 same person. We were interested in testing for a difference in adult body mass and thus kept in

167 the analysis only the measures made at one year of age and older.

168

169 Behavioural and physiological trials

170 In total, 169 birds were tested for their exploration behaviour and, among these birds, 137 were

171 tested for handling aggression and 57 for heart rate. All behavioural and physiological traits were

172 measured once for each bird, which prevented us from reporting their repeatability. However,

173 these behavioural and physiological traits have been shown to be repeatable in these two

174 populations in the wild, with repeatability estimates ranging from 0.26 to 0.75 depending on the

175 trait (see Dubuc-Messier et al. 2017 for details). In the present study, exploration behaviour was

176 measured using a different protocol (see below) than the one used in the wild (Dubuc-Messier et

177 al. 2017). Nevertheless, we are confident that the exploration behaviour measured here represents

178 repeatable characteristics of the individuals because this measure has been shown to be repeatable

179 in blue tits in several studies using different protocols (Kluen \& Brommer 2013; Mutzel et al.

180 2013; Dubuc-Messier et al. 2017). For details regarding the phenotyping of wild birds used in the

$181 \mathrm{P}_{\mathrm{st}}$ calculations, please refer to Dubuc-Messier et al. (2017).

182

183 Exploration behaviour

184 Exploration behaviour trials were done in fall 2011 in the Netherlands Institute of Ecology as 185 described by Reparaz et al. (2014) and using a novel environment chamber slightly modified

186 from Drent et al. (2003). The novel environment chamber consisted of a $4.0 \times 2.4 \times 2.5 \mathrm{~m}$ room 187 with five artificial trees. Individuals were placed in cages adjacent to the main chamber 30 to 120 
188 minutes before the trials and introduced in the main chamber through a sliding door. For two

189 minutes, the observer counted the number of movements between trees and the number of small 190 jumps on a given tree / branch. Exploration scores was the sum of both and varied from 10 (a 191 very slow exploration pattern) to 92 (a very fast exploration pattern; Reparaz et al. 2014).

193 Handling aggression

194 Handling aggression was measured assessing the bird's aggression towards a manipulator 195 (Dubuc-Messier et al. 2017). We used a score ranging from 0 to 3. A score of 0 was the lowest 196 aggression score (no reaction; high docility) and 3 the highest (see Table S2 for detailed protocol). 197 Handling aggression was recorded in 2012 and 2015 at the CEFE-CNRS (France). Birds from the 1982010 cohort were tested for handling aggression in 2012 or 2015 (at 2 or 5 years of age), while 199 the entire cohort from 2011 was tested for handling aggression in 2015 (at 4 years of age). 200 Handling aggression score was assessed blindly with respect to habitat of origin in 2015 and was 201 assessed by two different observers, one in 2012 and one in 2015.

203 Heart rate during manual restraint

204 Heart rate was recorded in 2012 at the CEFE-CNRS (for the 2010 cohort only), as described by 205 Dubuc-Messier et al. (2017). Within a few minutes after capture, we recorded heart rate for 30 206 seconds using a digital recorder. We used the software Avisoft SASLab Pro version 5.1 to extract 207 the mean time interval (sec) between two heartbeats using approximately 100 consecutive 208 heartbeats per individual. 
210 Molecular markers and $\mathrm{F}_{\mathrm{st}}$ calculation

211 For logistical reasons, we were not able to perform a molecular analysis on the birds used in the 212 common garden experiment. As an alternative, we used a dataset, published by Szulkin et al. 213 (2016) of wild birds from these two populations (i.e. deciduous, $\mathrm{n}=49$; evergreen, $\mathrm{n}=83$ 214 individuals) and genotyped at several thousand SNP using RAD-sequencing. We retained loci 215 genotyped over at least $75 \%$ of the individuals. To avoid bias during filtering and in the $F_{\text {st }}$ 216 estimates, we pruned highly related individuals from the dataset to keep only individuals linked 217 with values of kinship lower than 0.05 (coefficient of Loiselle; Loiselle et al. 1995; Cheverud 218 1996) computed in Genodive 2.27 (Meirmans \& Van Tienderen 2004). In order to retain loci 219 more likely to be informative, we applied a 5\% MAF threshold (Minor Allele Frequency, using 220 vcftools 0.1.11; Danecek et al. 2011). We pruned the dataset for SNPs that deviated from Hardy221 Weinberg-Equilibrium in at least one of the two populations ( $p$-value $<0.05$ ) using vcftools 222 0.1.11. We retained only the first SNP of each 100 bp locus. To obtain a set of SNPs more likely 223 to be neutral, we filtered out SNPs potentially under divergent selection between the two habitats

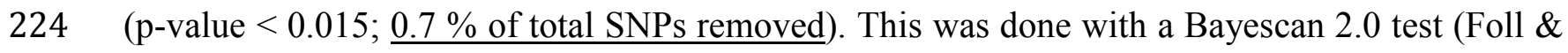
225 Gaggiotti 2008; 5000 pilot iterations, 50000 burnin, prior odds of 100). Average $\mathrm{F}_{\text {st }}$ and $95 \%$ 226 confidence intervals were estimated using the R-package hierfstat 0.04-22 (Goudet 2005). The 227 final dataset contained 69 individuals (32 and 37 individuals in the deciduous and evergreen 228 habitats, respectively) genotyped at 5407 SNPs.

230 Statistical analysis

231 Genetic divergence between habitats of origin

232 We tested for a genetic difference between the two habitats for each trait with univariate linear 233 mixed-models using the phenotype of each bird as a response variable and habitat of origin, sex, 
234 and their interaction as fixed effects. When we found a significant interaction between habitat of

235 origin and sex, we ran a separate model for each sex. Specific confounding variables were added 236 as fixed effects for each particular trait. For exploration score, we added a cohort term as fixed 237 effect to test for any environmental effect early in life or during the hand-rearing period in 238 captivity. Novel environment tests were done on the two cohorts at the same time (in autumn 239 2011). Thus, at the time of the test, individuals born in 2010 were almost $1 \frac{1 / 2}{2}$ years old, while 240 individuals born in 2011 were 5 months old. Hence, in this model, the cohort term controlled for 241 the combined effect of cohort and age. For handling aggression score, we added cohort, time of 242 day (hour), and year of test (2012 or 2015) as fixed effects. For heart rate models, we added as 243 fixed effect mean individual adult body mass because heart rate is related to the metabolic rate 244 and both are positively related to body mass (Green et al. 2011). Heart rate recordings were done 245 in 2012 on the 2010 cohort only. We therefore did not add a fixed effect for bird age, cohort or 246 year to avoid redundancy. We also added in heart rate models the time of day (hour) as a fixed 247 effect. For body mass, we added age as a continuous variable, cohort, and time of day (hour). For 248 tarsus length, we added cohort only as fixed effect (i.e. 2010 and 2011).

250 In all models, we used random intercepts for the brood of origin and rearing brood to account for 251 the non-independence of birds coming from the same brood or / and the effect of foster parents 252 for nestlings that have been cross-fostered prior to the captivity period. Because body mass was 253 measured several times for each bird, we also added a random intercept for bird identity for this 254 trait.

255

256 All response variables were Z-transformed prior to analyses. We tested the significance of the 257 fixed effects and selected a minimal models by LRT (log likelihood ratio test) in a stepwise 
258 elimination procedure starting with a model that included all variables (Bates et al. 2014). We 259 kept all the random effects in final minimal models. We present in Table S3 the L-ratios and p260 values associated with all variables in initial models. Analyses were done with $R$ (R Core Team 261 2017) using the function lmer of the package lme4 (Bates et al. 2015). Confidence intervals 262 (95\%) were generated with the function confint.merMod (lme4). We assumed a Gaussian 263 distribution for all traits, which was confirmed after visual inspection of the residuals. We also 264 evaluated the population of origin effect across all five traits using Fisher's combined probability 265 test run with the sumlog function of the R package metap (Dewey 2017).

$267 \mathrm{Q}_{\mathrm{st}}, \mathrm{P}_{\mathrm{st}}$ and $\mathrm{F}_{\mathrm{st}}$ comparison

268 Because birds were raised in a common garden, we considered that a phenotypic difference 269 among individuals was a realistic approximation of an additive genetic effect. For each trait, we 270 thus calculated the $\mathrm{Q}_{\mathrm{st}}$ between the two habitats based on the phenotypes of birds from the 271 common garden using a procedure similar to Bertrand et al. (2016) with univariate mixed models 272 in a Bayesian framework. We calculated $\mathrm{Q}_{\mathrm{st}}$ as:

273

$274 \mathrm{Q}_{\mathrm{st}}=\sigma_{\mathrm{B}} /\left(\sigma_{\mathrm{B}}+2 * \sigma_{\mathrm{W}}\right)$

275

276 Where $\sigma_{\mathrm{B}}$ is the between-habitat phenotypic variance and $\sigma_{\mathrm{W}}$ the within-habitat variance (or 277 residual; Wright 1949). The two variance components were extracted from a univariate linear 278 mixed model including habitat of origin (and identity of the bird for body mass) as random 279 intercepts. We also included the fixed effects structure selected previously (minimal model) 280 excluding the term habitat of origin. We calculated $\sigma_{\mathrm{B}}$ as the variance attributable to the habitat 
281 of origin and $\sigma_{\underline{W}}$ as the residual variance (or for body mass as the sum of the variance attributable

282 to the residual and to the individual identity; Bertrand et al. 2016). We did not include any broods

283 effects in these models because the variance attributable to the brood is also attributable to the

284 population of origin. We present the between-habitat variance for each study trait extracted from

285 the models used to calculate $\mathrm{Q}_{\mathrm{st}}$ in Table S5. We calculated $\mathrm{P}_{\mathrm{st}}$ as $\mathrm{Q}_{\mathrm{st}}$ but used as random 286 intercepts habitat of origin, the identity of the bird and the observer identity (for handling 287 aggression and heart rate) along with the significant fixed effects detailed in Dubuc-Messier et al.

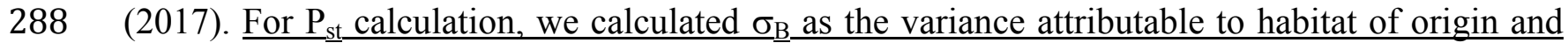
$289 \underline{\sigma}_{\mathrm{W}}$ as the sum of the variance attributable to the observer, to the residual variance and the 290 individual identity.

292 These models were performed with MCMCglmm package (Hadfield 2010) in R using slightly 293 informative priors (i.e. $\mathrm{V}=\mathrm{V}_{\mathrm{P}} / \mathrm{n}, n u=1$ or $0.5 ; \mathrm{V}_{\mathrm{P}}$ is the total phenotypic variance of the trait 294 and $\mathrm{n}$ the number of random effects), 10 million iterations, a thinning of 200 and a burn-in phase 295 of 500 . Because the results of the models with different $n u$ were similar, we used the posterior 296 distribution of models with $n u=1$ in $\mathrm{Q}_{\mathrm{st}}$ and $\mathrm{P}_{\mathrm{st}}$ calculations. We assessed the presence of 297 autocorrelation with the function autocorr (MCMCglmm package). All models showed an 298 autocorrelation less than $10^{-4}$. We checked for model convergence with the function gewe.diag of 299 the coda package (Plummer et al. 2006). For all traits, we calculated the ratio $\mathrm{Q}_{\mathrm{st}} /$ mean $\mathrm{F}_{\mathrm{st}}$ for 300 each sample of the posterior distribution and report the posterior mode of the ratio and its $95 \%$ 301 credibility intervals (calculated using the HPDinterval function of the package lme4). We 302 assumed that $\mathrm{Q}_{\mathrm{st}}$ differed significantly from $\mathrm{F}_{\text {st }}$ when the credibility interval around the ratio did 303 not include one. 


\section{Results}

306 Divergence between habitats of origin

307 The Fisher combined probability test method on all studied traits indicated an overall significant

308 effect of the habitat of origin (chi-squared : 54.647, $\mathrm{df}=10$ and $\mathrm{p}$-value $<0.001$ ). Below we

309 present the results for each trait separately.

311 Behavioural and physiological traits

312 For birds in the common garden experiment, habitat of origin had a significant effect on the two

313 behavioural traits: blue tits from the deciduous habitat were faster explorers and were more

314 aggressive to the handler (Table 1; Fig. 1). Birds from the deciduous habitat had a lower heart

315 rate than birds from the evergreen habitat (Table 1; Fig. 1). We found a trend for an interaction

316 between habitat of origin and sex for heart rate $($ L-ratio $=3.360$, d.f. $=1$, p-value $=0.067)$ :

317 evergreen males had a higher heart rate than deciduous males [estimate $=1.24$ (95\% CI: 0.31 ;

318 2.17), $\mathrm{L}$-ratio $=6.260$, d.f. $=1$, p-value $=0.010]$ but there was no habitat of origin effect for

319 females $(\mathrm{L}$-ratio $=2.150$, d.f. $=1$, $\mathrm{p}$-value $=0.142)$. There was no interaction between sex and

320 habitat of origin for the two behavioural traits, but there was a difference in exploration score

321 between sexes (Table 1).

322

323 Morphological traits

324 Habitat of origin also had a significant effect on the two morphological traits: deciduous birds

325 were heavier and had a longer tarsus than evergreen birds (Table 1; Fig. 1). We did not find any

326 interaction between habitat of origin and sex for these two traits (tarsus length: L-ratio $=0.226$, 
327 d.f. $=1$, p-value $=0.634$; body mass: L-ratio $=0.155$, d.f. $=1$, p-value $=0.694)$. Among-

328 individual differences in body mass were significant and represented $45 \%$ of the total variance of

329 the trait [variance $=0.34(95 \%$ CI: 0.26; 0.46), L-ratio $=421.95, \mathrm{p}$-value $<0.001]$.

$331 \quad$ Brood effects

332 Differences among broods of origin explained a significant portion (78\%) of the total phenotypic 333 variance in body mass, but not for the other traits (Table S4). Differences among rearing broods 334 explained a significant portion of the total variance in tarsus length $(22 \%)$ and a marginally 335 significant portion of total variance in heart rate $(30 \%$, p-value $=0.07)$ but not for the other traits.

$337 \mathrm{Q}_{\mathrm{st}}, \mathrm{P}_{\mathrm{st}}$ and $\mathrm{F}_{\mathrm{st}}$ comparison

338 We found a significant but small genetic differentiation between the two populations [mean $\mathrm{F}_{\text {st }}$ 339 over all loci $=0.004$ (95\% CrI: 0.003; 0.005), p-value $<0.001]$. $\mathrm{Q}_{\text {st }}$ was higher than $\mathrm{F}_{\text {st }}$ with non-

340 overlapping intervals for all traits. The ratio between the $\mathrm{Q}_{\mathrm{st}}$ and $\mathrm{F}_{\mathrm{st}}$ was significantly greater than 341 one for all traits. Credibility intervals for $\mathrm{Q}_{\mathrm{st}}$ and $\mathrm{P}_{\mathrm{st}}$ overlapped for all traits (Table 2).

\section{Discussion}

344 Our common garden experiment suggests a genetic divergence in personality, physiological and

345 morphological traits between two blue tit populations inhabiting contrasted habitats separated by

346 a small spatial distance in regards to the species dispersal capacity. Adult blue tits originating 347 from the evergreen habitat displayed slower exploration behaviour, lower handling aggression

348 (higher docility), faster heart rate, lower body mass and shorter tarsus compared to birds from the

349 deciduous habitat (Table 1; Fig. 1). These differences are similar to the ones measured in the wild 
350 suggesting that plasticity alone is not responsible for the observed phenotypic divergence in the 351 wild (Charmantier et al. 2016; Dubuc-Messier et al. 2017). In addition, we found a significant $F_{\text {st }}$ 352 between the two populations, but its low value (0.004) indicates current or past gene flow, in 353 concordance with previous findings (Szulkin et al. 2016). The $\mathrm{Q}_{\mathrm{st}}-\mathrm{F}_{\mathrm{st}}$ comparisons revealed that 354 blue tits from these populations are more differentiated for personality, physiological and 355 morphological traits then they are at the genome-wide level (Table 2). These results suggest that 356 genetic drift alone does not explain the observed divergence between the two populations and 357 that differences in selection regimes are responsible for this divergence.

359 The divergence we describe in personality, physiological and morphological traits is likely to be 360 mainly of genetic origin, since birds from both habitats were raised in identical conditions from 361 their first week of life to up to five years. In addition, the divergence found in this study for adult 362 body size is consistent with previous studies that have found divergent selection between the two 363 populations for morphological traits (Blondel et al. 2002; Teplitsky et al. 2014) and moderate to 364 high heritability for these traits (0.29 to 0.51; Teplitsky et al. 2014). However, we cannot 365 completely exclude that early environmental effects such as non genetic inheritance, occurring 366 before the chicks were sampled from their nest were at least partly responsible for the observed 367 patterns (Kruuk \& Hadfield 2007; Räsänen et al. 2007; Bonduriansky \& Day 2009; Bouwhuis et 368 al. 2010; van Oers et al. 2015). Such early environmental effects might be particularly important 369 for tarsus length, which is usually fixed at fifteen days of age for this species. However, for 370 behavioural traits, such strong environmental effects lasting for up to five years are unlikely, 371 since very few studies have reported long-term consequences of early environmental conditions 372 for the studied traits (Taylor et al. 2012; Petelle et al. 2015) and because maternal effects are 373 known to decrease during ontogeny (Cheverud et al. 1983; Wilson et al. 2007). One way to 
374 control for very early environmental effects would be to allow the birds to breed in captivity and

375 compare the phenotypes in the offspring generation. However, this type of experiment presents

376 significant challenges that have so far prevented their feasibility in our study system. In

377 particular, while it is possible to maintain blue tits in aviaries for short time experiments (Reparaz

378 et al. 2014) it is difficult to make them breed in captivity (Lambrechts et al. 1999).

380 Some studies have raised concerns regarding $\mathrm{Q}_{\mathrm{st}}$ and $\mathrm{F}_{\mathrm{st}}$ estimation and their comparison 381 (Leinonen et al. 2013). In particular between-population variance and thus $\mathrm{Q}_{\mathrm{st}}$ estimation may be 382 imprecise when a small number of populations are compared like it is the case in our study 383 (O’Hara and Mërila 2005; Leinonen et al. 2013). However, simulations have shown that a small 384 number of populations results in a downward bias in $\mathrm{Q}_{\text {st }}$ estimation when $\mathrm{Q}_{\text {st }}$ is high (O'Hara and 385 Mërila 2005). Another important concern is whether genetic markers involved in $\mathrm{F}_{\text {st }}$ estimation 386 are truly neutral (Leinonen et al. 2013). In this study, we used an $\mathrm{F}_{\mathrm{st}}$ calculated from markers that 387 included the whole genome. Although we filtered SNPs under potential divergent selection, it is 388 possible that we included potentially non-neutral regions (or that we removed some neutral ones).

389 However, using microsatellites, Porlier et al. (2012) have found a lower $F_{\text {st }}(0.001)$ between the 390 same populations during a similar time period (year 2009). Hence, although $\mathrm{Q}_{\text {st }}$ and $\mathrm{F}_{\text {st }}$ 391 comparison have some limitations, these limitations should most probably have limited our 392 capacity to detect significant $\mathrm{Q}_{\mathrm{st}}-\mathrm{F}_{\mathrm{st}}$ differences rather than reveal false differences.

394 Environmental heterogeneity, divergent selection and local adaptations

395 The importance of environmental heterogeneity and gene flow for phenotypic divergence has 396 mainly been studied for life history and morphological traits and much less for behavioural traits. 397 Indeed, few studies have disentangled so far the role of plasticity from that of genetic differences 
398 in shaping the phenotypic divergence of populations for behavioural traits (Bell 2005; 399 Dingemanse et al. 2007; Herczeg et al. 2013; Karlsson et al. 2016; Jacquin et al. 2016) and even 400 fewer for highly mobile avian species (Atwell et al. 2012; Miranda et al. 2013). In addition, to 401 our knowledge, no studies has until now reported $\mathrm{Q}_{\mathrm{st}}-\mathrm{F}_{\mathrm{st}}$ comparisons involving personality 402 traits. This shortage of study is probably due to the fact that personality traits are often considered 403 plastic and thus less prone to genetic divergence and local adaptations than morphological traits. 404 Yet, the results of our study suggest a genetic divergence for personality traits and that this 405 divergence could be as strong as for morphological traits (Table 1 and 2).

407 Past studies in this system and on personality variation suggest that the genetic divergence found 408 here could be the result of the coevolution of multiple types of traits in response to the ecological 409 context of each habitat. Indeed, an increasing number of studies are suggesting that life-history 410 and personality traits could have co-evolved to form a pace-of-life syndrome (Réale et al. 2010).

411 For example, empirical and theoretical studies are suggesting that high investment in early 412 reproduction at a cost of reduced residual reproductive value (either via survival or future 413 reproduction) should be associated with boldness, fast exploration, and high aggressiveness 414 (Réale et al. 2010; Wolf et al. 2007). Our results on this system are consistent with the pace-of415 life syndrome hypothesis. Blue tits from the deciduous habitat, which are more aggressive and 416 faster explorers, have a shorter lifespan and a lower residual reproductive value, but larger clutch 417 sizes than birds from the evergreen habitat (Grosbois et al. 2006; Charmantier et al. 2016; 418 Dubuc-Messier et al. 2017; Table S1). Our results suggest that these divergences for personality 419 traits are genetic and the $\mathrm{Q}_{\mathrm{st}}-\mathrm{F}_{\mathrm{st}}$ comparisons revealed that they are likely the result of divergent 420 selection pressures rather than drift. In addition, studies on other blue tit or great tit (Parus major) 421 populations have found that the personality phenotype is heritable and related to fitness (van Oers 
422 \& Sinn 2011; Class et al. 2014). Therefore, taken together, our results suggest that the personality

423 phenotypes of birds living in these habitats could have evolved and be implicated in blue tit

424 adaptation to local ecological conditions prevailing in each habitat.

425

426 Brood effects

427 We did not find any significant brood-of-origin effect for handling aggression, exploration score,

428 heart rate, and tarsus length. Since all these traits except heart rate have been shown to be

429 heritable in previous studies on blue tits (van Oers \& Sinn 2011; Class et al. 2014; Teplitsky et al.

430 2014), the absence of heritable variance in our analysis is most probably explained by the

431 relatively small number of broods. Estimating heritability was not the goal of this study, we only

432 wanted to control for dependence issues associated with the use of sibs.

433

434 The partial cross-fostering manipulation before the common garden experiment revealed a 435 significant rearing brood effect for tarsus length. This result suggests that the rearing environment 436 between 2 days to 12 days old can have a significant impact on this morphological trait. 437 Contrarily to the other traits that are more labile, tarsus length generally stabilises at fifteen days 438 of age in blue tits. We were, therefore, able to capture the early environmental effect for this trait 439 by measuring the adult phenotype. We found a marginally significant brood of rearing effect for 440 heart rate but not for other traits. There may be several reasons for such results. First, these traits 441 may not be sensitive to the rearing environment. Second, it is possible that - as for brood of origin 442 - these traits are slightly sensitive to early environmental effect (2 to 12 days) but that we lack 443 power to detect it. 
445 Genetic and environmental effects are not mutually exclusive

446 Genetic divergence does not preclude a plastic response to ecological conditions specific to each

447 habitat. For example, in the wild, the phenotypic difference in male heart rate between habitats

448 was not significant (Dubuc-Messier et al. 2017), but using the common garden experiment we

449 found here a significant difference in male heart rate. It is thus possible that plastic responses of

450 heart rate to habitat specific ecological conditions in the wild may have hidden the genetic

451 divergence (Conover \& Schultz 1995). In addition, the important temporal variation in mean

452 handling aggression in the wild shown by Dubuc-Messier et al. (2017) in each population,

453 suggests that individuals can partly adjust their personality phenotype for this trait depending on

454 the current local conditions. However, for all traits, the $\mathrm{P}_{\text {st }}$ between wild birds was not

455 statistically different from their $\mathrm{Q}_{\text {st }}$, suggesting that environmental effects in the wild might not

456 result in stronger or weaker differentiation compared to the genetic differentiation.

458 Conclusion

459 Our study suggests a genetic divergence for personality, physiological and morphological traits 460 between two blue tit populations that occupy different habitats but that are separated by small 461 spatial distances compared to the dispersal ability of the species and connected by gene flow. The 462 present study and past results for this system suggest that these differences are likely due to 463 different selection pressures and may represent local adaptations. These results thus emphasize 464 the role of environmental heterogeneity for intra-specific phenotypic diversity and suggest that 465 genetic population divergence is possible at small spatial scales (relative to their dispersal ability) 466 for behavioural traits. 


\section{Acknowledgements}

469 We thank the landowners for permission to work on their properties and all the blue tit crew for 470 their work. We declare no conflict of interests.

471

\section{Data accessibility}

473 The dataset will be shared on dryad upon publication.

474

\section{$475 \quad$ References}

476 Atwell, J.W., Cardoso, G.C., Whittaker, D.J., Campbell-Nelson, S., Robertson, K.W. \& Ketterson, E.D. 2012. Boldness behavior and stress physiology in a novel urban environment suggest rapid correlated evolutionary adaptation. Behav. Ecol 23: 960-969. doi:10.1093/beheco/ars059.

481 Bates, D., Mächler, M., Bolker, B.M., \& Walker, S.C. 2014. Fitting linear mixed-effects models using lme4. available at https://cran.r-project.org/web/packages/lme4/vignettes.

483

484 Bates, D., Maechler, M., Bolker, B., \& Walker, S. 2015. Fitting linear mixed-effects models 485 using lme4. J. Stat. Softw. 67: 1-48.

486

487

Bell, A.M. 2005. Behavioural differences between individuals and two populations of 488 Stickleback (Gasterosteus Aculeatus). J. Evol. Biol. 18: 464-473. 
490 Bertrand, J. A., Delahaie, B., Bourgeois, Y. X., Duval, T., García $\square$ Jiménez, R., Cornuault,

491

492

493

494

495

496

497

498

499

500

501

502

503

504

505

506

507

508

509 Cheverud, J.M., \& Marroig, G. 2007. Comparing covariances matrices: random skewers method

510

511

512 Class, B., Kluen, E., \& Brommer, J.E. 2014. Evolutionary quantitative genetics of behavioral 513

J., Pujol, B., Thébaud, C., Milá, B. (2016). The role of selection and historical factors in driving population differentiation along an elevational gradient in an island bird. J. Evol. Biol. 29: 824-836.

Blondel, J., Perret, P., Anstett, M.-C. \& Thebaud, C. 2002. Evolution of sexual size dimorphism in birds: test of hypotheses using Blue tits in contrasted mediterranean habitats. J. Evol. Biol. 15: 440-450.

Charmantier, A., Doutrelant, C., Dubuc-Messier, G., Fargevieille, A., \& Szulkin, M. 2016. Mediterranean Blue tits as a case study of local adaptation. Evol. Appl. 9: 135-152.

Cheverud, J.M. 1996. Developmental integration and the evolution of pleiotropy. Amer. Zool. 36: $44-50$.

Cheverud, J.M., Rutledge, J.J. \& Atchley, W.R. 1983. Quantitative genetics of development: genetic correlations among age-specific trait values and the evolution of ontogeny. Evolution 37: 895. compared to the common principal components model. J. Genet. Mol. Biol. 30: 461-469. responses to handling in a wild passerine. Ecol. Evol. 4: 427-440. 
515 Conover, D.O., \& Schultz, E.T. 1995. Phenotypic similarity and evolutionary significance of contergradient variation. Trends Ecol. Evol. 10: 248-252.

517

518 Danecek, P., Auton, A., Abecasis, G., Albers, C.A., Banks, E., DePristo, M.A., Handsaker, R.E.

519 et al. 2011. The variant call format and VCFtools. Bioinformatics 27: 2156-2158.

520

521 Dewey, M. 2017. metap: meta-analysis of significance values. R package version 8.0.

522

523 Dingemanse, N. J., Wright, J., Kazem, A. J., Thomas, D. K., Hickling, R. Dawnay, N. 2007.

524 Behavioural syndromes differ predictably between 12 populations of three $\square$ spined

525 stickleback. J. Animal Ecol. 76: 1128-1138.

526

527 Drent, P.J., van Oers, K. \& van Noordwijk, A.J. 2003 Realized heritability of personalities in the 528 Great Tit (Parus Major). Proc. R. Soc. B 270: 45-51.

529

530 Dubuc-Messier, G., Réale, D., Perret, P. \& Charmantier, A. 2017. Environmental heterogeneity and population differences in Blue tits personality traits. Behav. Ecol. 28: 448-459.

532

533 Edelaar, P \& Bolnick, DI. 2012. Non-random gene flow: an underappreciated force in evolution 534 and ecology. Trends Ecol. Evol. 27: 659-665.

535

536 Fitzpatrick, B.M. 2012 Underappreciated consequences of phenotypic plasticity for ecological 537 speciation. Int. J. Ecol. 2012: 1-12. 
539 Foll, M. \& Gaggiotti, O. 2008 A genome-scan method to identify selected loci appropriate for both dominant and codominant markers: A bayesian perspective'. Genetics 180: 977-993.

542 Goudet, J. 2005. HIERFSTAT, a package for R to compute and test hierarchical F-Statistics'. Mol. Ecol. Notes 5:184-86.

544

545 Green J A. 2011. The heart rate method for estimating metabolic rate: review and 546 recommendations. Comp. Biochem. Physiol. A. Mol. Integr. Physiol. 158:287-304.

547

548 Grosbois, V., Henry, P.-Y., Blondel, J., Perret, P., Lebreton, J.-D., Thomas, D.W. et al. 2006.

549 Climate impacts on mediterranean Blue Tit survival: an investigation across seasons and 550 spatial scales. Glob. Change Biol. 12: 2235-2249.

551

552 Hadfield, J. 2010. MCMC methods for multi-response generalized linear mixed models: The 553 MCMCglmm R Package. J. Stat. Softw. 33:1-22.

554

555 Herczeg, G., Ab Ghani, N.I. \& Merilä, J. 2013. Evolution of Stickleback feeding behaviour: 556 genetics of population divergence at different ontogenetic stages. J. Evol. Biol. 26: 955962.

558

559 Jacquin, L., Reader, S.M., Boniface, A., Mateluna, J. Patalas, I., Pérez-Jvostov, F et al. 2016. 560 Parallel and nonparallel behavioural evolution in response to parasitism and predation in 561 Trinidadian guppies. J. Evol. Biol. 29: 1406-1422. 
563 Kawecki, T.J. \& Ebert, D. 2004 Conceptual issues in local adaptation. Ecol. Lett. 7: 1225-1241.

564

565 Kluen, E., \& Brommer, J.E. 2013. Context-specific repeatability of personality traits in a wild 566 bird: A reaction-norm perspective. Behav. Ecol. 24: 650-658.

567

568 Koolhaas, J.M., Korte, S.M., De Boer, S.F., Van Der Vegt, B.J., Van Reenen, C.G., Hopster, H., 569 D et al. 1999. Coping styles in animals: Current status in behavior and stress-physiology.

$570 \quad$ Neurosci. Biobehav. Rev. 23: 925-935.

571

572 Kruuk, L.E.B., \& Hadfield, J.D. 2007. How to separate genetic and environmental causes of 573 similarity between relatives: separating genetic and environmental effects. J. Evol. Biol. $574 \quad 20: 1890-1903$.

575

576 Lambrechts, M.M., Blondel, J., Hurtez-Bousses, S., Maistre, M. \& Perret, P. 1997. Adaptive 577 inter-population differences in Blue tit life-history traits on Corsica. Evol. Ecol. 11: 599612.

580 Lambrechts, M. M., Perret, P., Maistre, M., and Blondel, J. 1999. Do experiments with captive 581 non-domesticated animals make sense without population field studies ? A case study with blue tits' breeding time. Proc. R. Soc. B 266:1311-13.

583

584 Laurila, A., S. Karttunen, S. \& J. Merila. 2002. Adaptive phenotypic plasticity and genetics of 585 larval life histories in two Rana temporaria populations. Evolution 56:617-627. 
587 Leinonen,T., McCairns, R.J.S., O’Hara, R.B. \& Merilä, J. 2013. QST-FST comparisons: 588 evolutionary and ecological insights from genomic heterogeneity. Nat. Rev. Genet. 14: $589 \quad 179-190$.

590

591 Lenormand, T. 2002. Gene flow and the limits to natural selection. Trends Ecol. Evol. 17: 183592 189.

593

594

Loiselle, B.A., Sork, V.L., Nason, J. \& Graham, C. 1995. Spatial genetic structure of a tropical 595 understory shrub, Psychotria Officinalis (Rubiaceae). Am. J. Bot. 82: 1420.

596

597

Meirmans, P.G., \& Van Tienderen, P.H. 2004. Genotype and Genodive: Two programs for the 598 analysis of genetic diversity of asexual organisms. Mol. Ecol. Notes 4: 792-794.

599

600 Miranda, A.C., Schielzeth, H., Sonntag, T. \& Partecke, J. 2013. Urbanization and its effects on 601

602 personality traits: A result of microevolution or phenotypic plasticity? Glob. Change Biol. 19: $2634-2644$.

603

604

Mutzel, A., Dingemanse, N.J., Araya-Ajoy, Y.G. \& Kempenaers, B. 2013. Parental provisioning 605

606 behaviour plays a key role in linking personality with reproductive success. Proc. R. Soc. B 280: 20131019-20131019.

608 Petelle, M.B., Martin, J.G.A. \& Blumstein, D.T. 2015. Heritability and genetic correlations of 609 personality traits in a wild population of Yellow-Bellied Marmots (Marmota Flaviventris). J. Evol. Biol. 28: 1840-1848. 
611 Pigliucci, M. 2005 Evolution of phenotypic plasticity: Where are we going now? Trends Ecol. Evol. 20: 481-86.

613

614 Plummer, M., Best, N., Cowles, K., \& Vines, K. 2006. CODA: Convergence diagnosis and 615 outpus analysis for MCMC. R News 6: 7-11.

617 Porlier, M., Garant, D., Bourgault, P., Perret, P., Blondel, J. \& Charmantier A. 2012. Habitat618 linked population genetic differentiation in the Blue tit Cyanistes caeruleus. Journal of Heredity 103: 781-791.

620

621 R Core Team. 2017 R: A language and environment for statistical computing. R Foundation for 622 Statistical Computing. URL Http://www.R-Project.org/. Accessed January 15. 624 https://www.r-project.org/.

Réale, D., Berteaux, D.A., McAdam, A.G. \& Boutin, S. 2003 Lifetime selection on heritable life627

628 Réale, D., Garant, D., Humphries, M.M., Bergeron, P., Careau, V. \& Montiglio, P.-O. 2010. 629 personality and the emergence of the pace-of-life syndrome concept at the population level. Proc. R. Soc. B 365: 4051-4063.

631 temperament within ecology and evolution. Biol. Rev. 82, 291-318. 
635 Reparaz, L.B., van Oers, K., Naguib, M., Doutrelant, C., Visser, M.E. \& Caro, S.P. 2014. Mate 636 preference of female Blue tits varies with experimental photoperiod. PLoS ONE 9: 637 e92527.

638

639

Revell, L.J. 2007. The G matrix under fluctuating correlational mutation and selection. Evolution

640 61: $1857-1872$.

641

642 Revell, L.J. 2012. Phytools: An R package for phylogenetic comparative biology (and other 643 things): Phytools: R Package. Methods Ecol. Evol 3: 217-23.

644

645 Richardson, J. L., Urban, M. C., Bolnick, D. I., \& Skelly, D. K. 2014. Microgeographic

646 adaptation and the spatial scale of evolution. Trends Ecol. Evol. 29:165-176.

647

648 Roff, D.A., \& Fairbairn, D.J. 2012. A test of the hypothesis that correlational selection generates 649 genetic correlations. Evolution 66: 2953-60.

650

651 Slatkin, M. 1987. Gene flow and the geographic structure of natural populations. Science 236: $652 \quad 787-792$.

653

654 Smith, B.R. \& Blumstein, D.T. 2008. Fitness consequences of personality: A meta-analysis. $655 \quad$ Behav. Ecol. 19: 448-455.

656

657 Sultan, S.E. \& Spencer, H.G. 2002. Metapopulation structure favors plasticity over local 658 adaptation. Am. Nat. 160: 71-283. 
660 Szulkin, M., Gagnaire, P.-A., Bierne, N. \& Charmantier, A. 2016. Population genomic footprints 661 of fine-scale differentiation between habitats in mediterranean Blue tits. Mol. Ecol. 25:

662 $542-558$.

663

664 Taylor, R.W., Boon, A.K., Dantzer, B., Réale, D., Humphries, M.M., Boutin, S., Gorrell, J.C., 665 Coltman, D.W. \& McAdam, A.G. (2012) Low heritabilities, but genetic and maternal 666 correlations between red squirrel behaviours: G-matrix of red squirrel personality traits. J $667 \quad$ Evol. Biol. 25: 614-624.

668

669 Teplitsky, C., Tarka, M., Møller, A.P., Nakagawa, S., Balbontín, J., Burke, T.A., Doutrelant, C. et al. 2014. Assessing multivariate constraints to evolution across ten long-term avian studies. PLoS ONE 9: e90444.

672

673

van Oers, K., Kohn, G.M., Hinde, C.A. \& Naguib, M. 2015. Parental food provisioning is related 674 to nestling stress response in wild Great tit nestlings: implications for the development of

675 personality. Front. Zool. 12: 1-10.

676

van Oers, K., \& Sinn, D.L. 2011. Toward a basis for the phenotypic gambit: Advances in the 678 evolutionary genetics of animal personality. From Genes to Animal Behavior (eds M. Inoue-Murayama, S. Kawamura, and A. Weiss). pp. 165-183. Tokyo: Springer Japan.

680

681 Wang, I.J., \& Bradburd, G.S. 2014. Isolation by environment. Mol. Ecol. 23: 5649-5662.

682 
683 Weir, B. S. \& Cockerham, C. C. 1984. Estimating F $\square$ statistics for the analysis of population $684 \quad$ structure. Evolution 38:1358-1370.

685

686 Wilson, A.J., Pemberton, J.M., Pilkington, J.G., Clutton-Brock, T.H., Coltman, D.W. \& Kruuk, 687 L.E.B. 2007. Quantitative genetics of growth and cryptic evolution of body size in an 688 island population. Evol. Ecol. 21: 337-356.

689

690 Wright, S. 1949. The genetical structure of populations. Ann. Hum. Genet. 15: 323-354.

691 
692 Figure 1. Mean phenotypes of blue tits originating from two distinct populations and 693 habitats (deciduous and evergreen) in Corsica (France) and reared in a common garden. A) 694 exploration score, B) handling aggression score, C) heart rate during manual restraint (heart 695 beats/min.), D) tarsus length $(\mathrm{mm})$ and E) adult body mass (g). Boxplots on raw data, the 696 boxes represent the first and the third quartile, the lines represent the median, the ends of the 697 whiskers represent the minimum data in the $1.5 *$ the interquartile range, dots represent 698 extreme data. All differences are significant (see Table 1 for details). 
700 Table 1. Final models describing the phenotype of blue tits originating from two distinct 701 populations and habitats (deciduous and evergreen) in Corsica (France) and reared in a common 702 garden.

\begin{tabular}{ccccccc}
\hline Traits & Terms & Estimates & $95 \%$ CI & L-ratio & d.f. & p-value \\
\hline Exploration score & Intercept & -0.32 & $-0.62 ;-0.03$ & & & \\
& Habitat of origin & -0.48 & $-0.78 ;-0.19$ & 9.70 & 1 & 0.002 \\
& Sex & 0.26 & $0.004 ; 0.52$ & 3.97 & 1 & 0.046 \\
& Cohort & 0.88 & $0.59 ; 1.17$ & 23.91 & 1 & $<0.001$ \\
Handling aggression & & & & & & \\
& Intercept & 0.45 & $0.18 ; 0.72$ & & & \\
& Habitat of origin & -0.82 & $-1.18 ;-0.46$ & 14.96 & 1 & $<0.001$ \\
& & & & & & \\
Heart rate during restraint (HR) & Intercept & -0.57 & $-1.06 ;-0.09$ & & & \\
& Habitat of origin & 0.98 & $0.35 ; 1.62$ & 8.17 & 1 & 0.004 \\
& & & & & & \\
& Intercept & -1.07 & $-1.40 ;-0.74$ & & & \\
& Habitat of origin & -0.33 & $-0.63 ;-0.03$ & 4.46 & 1 & 0.034 \\
& Sex & -0.56 & $-0.77 ;-0.35$ & 25.08 & 1 & $<0.001$ \\
& Age & 0.27 & $0.21 ; 0.33$ & 74.23 & 1 & $<0.001$ \\
& Time of day & 0.09 & $0.07 ; 0.11$ & 75.50 & 1 & $<0.001$
\end{tabular}

703 The deciduous habitat, females, and cohort 2010 were set as references in models. Estimates are

704 from a model with the brood of rearing and brood of origin in random effect (and individuals

705 identity for body mass), variance estimates are shown in Table S4. L-ratio and p-values are from

706 the comparison of a full model and a model without the variable of interest. The p-values and L707 ratio associated with each parameter in initial models before selection are presented in Table S3. 
709 Table 2. $\mathrm{Q}_{\mathrm{st}}$ and $\mathrm{P}_{\mathrm{st}}$ values (posterior mode) for each trait (and 95\% credible interval $(\mathrm{CrI})$ ), mean

$710 \mathrm{~F}_{\mathrm{st}}$ and $\mathrm{Q}_{\mathrm{st}} / \mathrm{F}_{\mathrm{st}}$ ratio [posterior mode and associated 95\% CrI)] between two blue tits populations

711 originating from distinct populations and habitats (deciduous or evergreen) in Corsica (France) and

712 reared in a common garden.

\begin{tabular}{cccc} 
Traits & $\begin{array}{c}\mathrm{Q}_{\text {st }} \\
(95 \% \mathrm{CrI})\end{array}$ & $\begin{array}{c}\mathrm{P}_{\text {st }} \\
(95 \% \mathrm{CrI})\end{array}$ & $\begin{array}{c}\mathrm{Q}_{\mathrm{st}} / \mathrm{F}_{\text {st }} \text { ratio } \\
(95 \% \mathrm{CrI})\end{array}$ \\
& & & \\
\hline Exploration score & 0.084 & 0.063 & 20.982 \\
& $(0.029 ; 0.804)$ & $(0.018 ; 0.727)$ & $(7.266 ; 201.065)$ \\
Handling aggression & 0.129 & 0.045 & 32.309 \\
& $(0.034 ; 0.832)$ & $(0.011 ; 0.692)$ & $(8.525 ; 208.025)$ \\
Heart rate during manual & 0.101 & 0.032 & 25.320 \\
restraint (HR) & $(0.033 ; 0.846)$ & $(0.007 ; 0.562)$ & $(8.244 ; 211.475)$ \\
& 0.069 & 0.095 & 17.144 \\
Body mass & $(0.018 ; 0.736)$ & $(0.030 ; 0.773)$ & $(4.541 ; 183.998)$ \\
& 0.197 & 0.212 & 49.368 \\
Tarsus length & $(0.050 ; 0.872)$ & $(0.048 ; 0.864)$ & $(12.455 ; 217.881)$ \\
& & & \\
Mean $F_{s t}$ & 0.004 & & \\
& $(0.003 ; 0.005)$ & & \\
\hline
\end{tabular}

$713 \mathrm{Q}_{\mathrm{st}}$ have been calculated from the phenotype of birds raised in a common garden and $\mathrm{P}_{\text {st }}$ from the 714 phenotype of wild birds.

715

716 
717 Figure 1.
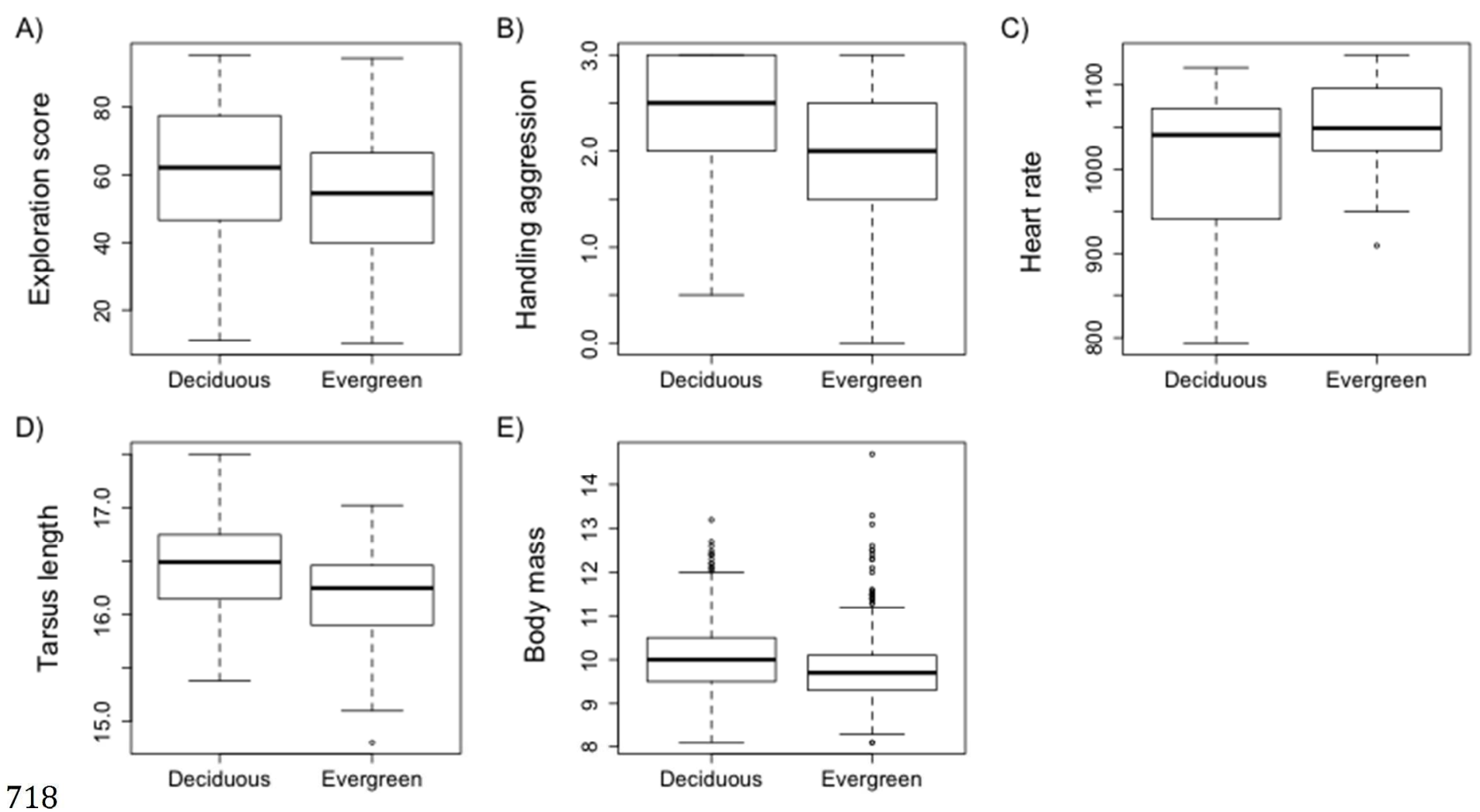

E)

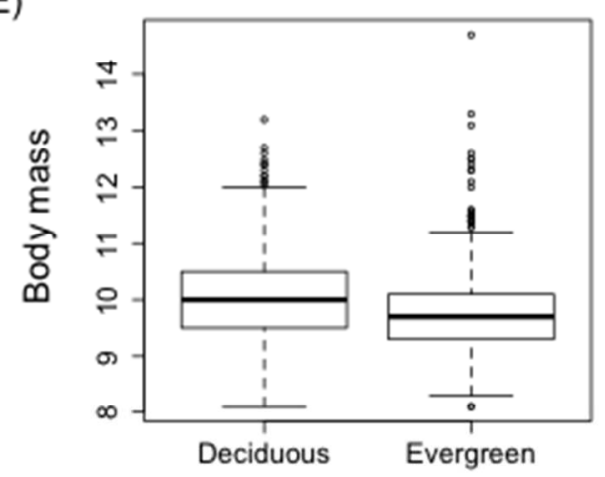

719 


\section{Online supporting information}

721 Table S1. Caterpillar abundance, life-history, morphological and personality phenotypes (mean

$722(n)$ ) of the two Corsican blue tit populations (France) in the wild.

723 Table S2. Blue tit handling aggression scale.

724 Table S3. L-Ratio, degree of freedom and p-values associated with each parameter in initial

725 models describing the phenotype of blue tits originating from two distinct habitats (deciduous

726 and evergreen) in Corsica (France) and reared in a common garden.

727 Table S4. Variance components, L-ratio and p-values for studied traits in two blue tits 728 populations in Corsica (France) reared in a common garden.

729 Table S5. Between-habitat variance (posterior mean and 95\% CrI) for each study trait extracted 730 from the models used to calculate Qst.

731

732 


\section{Online Supporting Information}

$\underline{\text { Average caterpillar abundance, life-history, morphological and personality phenotypes }}$

Table S1. Caterpillar abundance, life-history, morphological and personality phenotypes (mean $(n))$ of the two Corsican blue tit populations (France) in the wild.

\begin{tabular}{|c|c|c|}
\hline Populations & Deciduous & Evergreen \\
\hline First year of monitoring & 1993 & 1976 \\
\hline Caterpillar abundance $^{1}$ & 762.87 & 87.10 \\
\hline Annual adult survival probability ${ }^{2}$ & $0.391(6)$ & $0.574(14)$ \\
\hline Date of first egg laying $\left(1=\operatorname{March} 1^{\text {st }}\right)^{3}$ & $38.56(1233)$ & $70.08(1920)$ \\
\hline Male body mass $(\mathrm{g})^{3}$ & $9.82(1032)$ & $9.37(1607)$ \\
\hline Female body mass $(\mathrm{g})^{3}$ & $9.66(1153)$ & $9.23(1616)$ \\
\hline Male tarsus length $(\mathrm{mm})^{3}$ & $16.52(578)$ & $16.27(789)$ \\
\hline Female tarsus length $(\mathrm{mm})^{3}$ & $16.05(614)$ & $15.84(798)$ \\
\hline Clutch size $^{3}$ & $8.50(1235)$ & $6.61(1913)$ \\
\hline Number of fledglings ${ }^{3}$ & $6.60(1092)$ & $4.15(1273)$ \\
\hline Mean exploration speed $(\mathrm{cm} / \mathrm{s}) \pm$ s.d. ${ }^{4}$ & $13.52 \pm 8.39(176)$ & $10.37 \pm 7.49(117)$ \\
\hline Mean handling aggression score \pm s.d. ${ }^{4}$ & $1.69 \pm 0.95(703)$ & $1.49 \pm 0.99(549)$ \\
\hline Mean heart rate during manual restraint \pm s.d. ${ }^{4}$ & $963.30 \pm 87.80(159)$ & $976.24 \pm 86.99(91)$ \\
\hline
\end{tabular}

${ }^{1}$ mean maximal frass $\mathrm{mg} / \mathrm{m}^{2}$ per day in each population (sampled between 2011 and 2015 during the breeding period using $0.25 \mathrm{~m}^{2}$ trays placed under the forest canopy and collected twice a week, see Zandt et al. 1990 for details about the sampling procedure); ${ }^{2}$ Dubuc-Messier et al. In prep; ${ }^{3}$ Charmantier et al. 2016 (collected between the first year of monitoring and 2014); ${ }^{4}$ DubucMessier et al. 2016). 


\section{$\underline{\text { Handling aggression scores }}$}

The test was done within two minutes after capture and prior to any other manipulation. The handler held the bird with one hand and placed the bird's legs between his forefinger and his thumb to let the bird free to move its tails and wings. The handler pointed the forefinger of his other hand at a spot about 2 to $3 \mathrm{~cm}$ in front of the bird's beak and noted if the bird struck at his finger, and the position of its wings and tail. After two seconds in this position, the handler moved his forefinger towards the bird's beak two or three times and recorded its reaction.

Table S2. Blue tit handling aggression scale.

\begin{tabular}{|c|c|c|c|}
\hline Score & Wings spread & Tail feathers spread & Bird strikes fingers \\
\hline 0 & No & No & No \\
\hline 1 & No & No & Yes, but only if provoked \\
\hline 2 & No & Yes & Yes, spontaneously \\
\hline 3 & Yes & Yes & Yes, spontaneously \\
\hline
\end{tabular}

When the bird displayed one reaction specific to one score and another reaction specific to another score, it received an average score between the two. For example, a bird that struck without any provocation (score 2) but did not have its wings and tail feathers spread (score 1) would be scored as 1.5 . 


\section{$\underline{\text { Initial models }}$}

Table S3. L-Ratio, degree of freedom and p-values associated with each parameter in initial models describing the phenotype of blue tits originating from two distinct habitats (deciduous and evergreen) in Corsica (France) and reared in a common garden.

\begin{tabular}{|c|c|c|c|c|}
\hline Traits & Terms & L-ratio & d.f. & $\mathrm{p}$-value \\
\hline \multirow[t]{4}{*}{ Exploration score } & Cohort & 23.912 & 1 & $<0.001$ \\
\hline & Sex $*$ Habitat of origin & 1.104 & 1 & 0.293 \\
\hline & Sex & 3.970 & 1 & 0.046 \\
\hline & Habitat of origin & 9.697 & 1 & 0.002 \\
\hline \multirow[t]{6}{*}{ Handling aggression } & Time of day & 0.258 & 1 & 0.612 \\
\hline & Cohort & 0.052 & 1 & 0.819 \\
\hline & Year of trial & 0.001 & 1 & 0.973 \\
\hline & Sex $*$ Habitat of origin & 0.615 & 1 & 0.432 \\
\hline & Sex & 0.092 & 1 & 0.761 \\
\hline & Habitat of origin & 20.592 & 1 & $<0.001$ \\
\hline \multirow[t]{5}{*}{ Heart rate during restraint } & Mean body mass & 0.256 & 1 & 0.873 \\
\hline & Sex $*$ Habitat of origin & 3.3601 & 1 & 0.066 \\
\hline & Sex & 1.9081 & 1 & 0.167 \\
\hline & Habitat of origin & 9.012 & 1 & 0.003 \\
\hline & Time of day & 0.449 & 1 & 0.502 \\
\hline \multirow[t]{6}{*}{ Body mass } & Time of day & 75.500 & 1 & $<0.001$ \\
\hline & Age & 74.230 & 1 & $<0.001$ \\
\hline & Cohort & 0.014 & 1 & 0.905 \\
\hline & Sex $*$ Habitat of origin & 0.155 & 1 & 0.694 \\
\hline & Sex & 25.080 & 1 & $<0.001$ \\
\hline & Habitat of origin & 4.460 & 1 & 0.034 \\
\hline \multirow[t]{4}{*}{ Tarsus length } & Cohort & 0.350 & 1 & 0.554 \\
\hline & Sex $*$ Habitat of origin & 0.226 & 1 & 0.634 \\
\hline & Sex & 25.070 & 1 & $<0.001$ \\
\hline & Habitat of origin & 4.457 & 1 & 0.034 \\
\hline
\end{tabular}

The brood of rearing and brood of origin identity are fitted as random effect in all models (and individuals identity for body mass), variance estimates are shown in Table S3. L-ratio and pvalues are from the comparison of a full model and a model without the variable of interest. 


\section{$\underline{\text { Variance components }}$}

Table S4. Variance components (brood of origin, brood of rearing, and residuals), L-ratio, and pvalues for studied traits in two blue tits populations in Corsica (France) reared in a common garden.

\begin{tabular}{|c|c|c|c|c|c|c|c|c|c|}
\hline & Brood of origi & & & & Rearing brooc & & & & Residuals \\
\hline Traits & $\begin{array}{l}\text { Variance } \\
(95 \% \text { CI })\end{array}$ & L-ratio & d.f. & p-value & $\begin{array}{l}\text { Variance } \\
(95 \% \mathrm{CI})\end{array}$ & L-ratio & d.f. & $\begin{array}{c}\mathrm{p}- \\
\text { value }\end{array}$ & $\begin{array}{l}\text { Variance } \\
(95 \% \mathrm{CI})\end{array}$ \\
\hline $\begin{array}{l}\text { Exploration } \\
\text { score }\end{array}$ & $\begin{array}{c}0.05 \\
(0.00 ; 0.15)\end{array}$ & 0.76 & 1 & 0.38 & $\begin{array}{c}0 \\
(0.00 ; 0.001)\end{array}$ & 0 & 1 & 1 & $\begin{array}{c}0.71 \\
(0.56 ; 0.89)\end{array}$ \\
\hline $\begin{array}{l}\text { Handling } \\
\text { aggression }\end{array}$ & $\begin{array}{c}0.01 \\
(0.00 ; 0.13)\end{array}$ & 0.002 & 1 & 0.97 & $\begin{array}{c}0.08 \\
(0.00 ; 0.24)\end{array}$ & 1.52 & 1 & 0.22 & $\begin{array}{c}0.70 \\
(0.54 ; 0.94)\end{array}$ \\
\hline $\mathrm{HR}$ & $\begin{array}{c}0.05 \\
(0.00 ; 0.30)\end{array}$ & 0 & 1 & 1.00 & $\begin{array}{c}0.25 \\
(0.00 ; 0.70)\end{array}$ & 3.35 & 1 & 0.07 & $\begin{array}{c}0.66 \\
(0.42 ; 1.02)\end{array}$ \\
\hline Tarsus length & $\begin{array}{c}0.09 \\
(0.00 ; 0.29)\end{array}$ & 1.69 & 1 & 0.19 & $\begin{array}{c}0.14 \\
(0.01 ; 0.37)\end{array}$ & 4.74 & 1 & 0.03 & $\begin{array}{c}0.44 \\
(0.34 ; 0.57)\end{array}$ \\
\hline Body mass & $\begin{array}{c}0.07 \\
(0.01 ; 0.14)\end{array}$ & 4.10 & 1 & 0.04 & $\begin{array}{c}0 \\
(0.00 ; 0.001)\end{array}$ & 0 & 1 & 1.00 & $\begin{array}{c}0.02 \\
(0.22 ; 0.26)\end{array}$ \\
\hline
\end{tabular}

L-ratio and p-values are from the comparison of a full model and a model without the variable of interest. Bold indicates significant variance components. 
Table S5. Between-habitat variance (posterior mean and 95\% CrI) for each study trait extracted from the models used to calculate Qst.

\begin{tabular}{|c|c|}
\hline Traits & $\begin{array}{c}\text { Between habitat variance } \\
\mathbf{( 9 5 \%} \text { CrI) }\end{array}$ \\
\hline Exploration score & 1700 \\
$(11.88 ; 2464)$
\end{tabular}

\section{$\underline{\text { References }}$}

Charmantier A, Doutrelant C, Dubuc-Messier G, Fargevieille A, Szulkin M. 2016. Mediterranean blue tits as a case study of local adaptation. Evol Appl. 9(1): 135-52.

Dubuc-Messier G, Réale D, Perret P, Charmantier A. 2016. Environmental heterogeneity and population differences in blue tits personality traits. Behav Ecol.arw148.

Dubuc-Messier G, Charmantier A, Doutrelant C, Perret S, Pradel R, Choquet R, Réale D. In prep. Environmental heterogeneity and differential local selection patterns on personlaity traits in blue tits populations.

Zandt H, Strijkstra A, Blondel J, van Balen H. 1990. Food in two mediterranean blue tit populations: Do differences in caterpillar availability explain differences in timing of the breeding season? In Blondel J, Gosler A, Lebreton JD, McCleery R, editors. Population Biology of Passerine Birds: An Integrated Approach. Berlin: Springer-Verlag. Pages 145155. 